\title{
Anti-doping Awareness among British and Japanese Judo Coaches
}

Yoko Tanabe ${ }^{1^{*}}$, Colin Mclver $^{2}$, Joyce Heron ${ }^{2}$, Satomi Suzuki ${ }^{3}$ and Takao Akama ${ }^{4}$

${ }^{1}$ Nihon University, Japan

${ }^{2}$ British Judo Association, United Kingdom

${ }^{3}$ Waseda Institute for Sport Sciences, Japan

${ }^{4}$ Faculty of Sport Sciences, Waseda University, Japan

*Corresponding author: Yoko Tanabe, Nihon University, Japan, Tel: + 8103 59970213; E-mail: yoko-judo@lake.dti.ne.jp

Received date: March 14, 2017; Accepted date: April 7, 2017; Published date: April 14, 2017

Copyright: (C) 2017 Tanabe Y, et al. This is an open-access article distributed under the terms of the Creative Commons Attribution License, which permits unrestricted use, distribution and reproduction in any medium, provided the original author and source are credited.

\begin{abstract}
Objective: To reveal the understanding among judo coaches from different countries on anti-doping, and their understanding of how this is intrinsically valuable to sport.

Design: Survey study.

Participants: 74 British coaches (UK coaches) and 66 Japanese coaches (JPN coaches) certified by the British Judo Association or the All Japan Judo Federation, as appropriate.

Results: Most of both countries' coaches knew National Anti-Doping Organization and World Anti-Doping Agency. Almost of JPN coaches had attended an anti-doping workshop, however many of UK coaches had never attended such a workshop. There are aimed to compare the two countries' views of doping along the social, educational, ethical, and health-related aspects. The results from Question 7.1 (I agree with the act of doping), Question 7.6 (Doping enables judoka to improve their performance), and Question 7.9 (Prohibited substances are possibly included in certain legal medicines and food supplements) were significantly different between the UK coaches and JPN coaches groups.
\end{abstract}

Conclusions: Judo coaches around the world should be educated on anti-doping regimes

Keywords: Anti-doping; Education; Coach; Judo

\section{Introduction}

All athletes participating in competition are expected to strictly adhere to international rules and regulations governing their sport. Doping is fundamentally contrary to this intrinsic spirit of competition, and therefore damages competition integrity. Doping issues are a problem to be fought around the world in all sports, and doping among all athletes and coaches are strictly prohibited. The official stance of the International Olympic Committee Ethics 2012 (Dignity 3) that "All doping practices at all levels are strictly prohibited. The provision against doping in the World Anti-Doping Code shall be scrupulously observed [1]". The Anti-Doping Code, in turn, states that "The anti-doping programs seek to preserve what is intrinsically valuable about sports. This intrinsic value is often referred to as [2] 'the spirit of sport' [3]". Thomas Bach, president of the International Olympic Committee, noted in his opening speech at the 2013 World Conference on Doping in Sport "clean athletes" are an investment in the future of our sport. The future of sport greatly depends on our success in the fight against doping, any kind of manipulation and related corruption, because all their measures serve to protect the clean athletes [4]". It is difficult to establish a competition where athletes have only an understanding of competition rules. Rather, it is necessary for the future of sport for athletes, coaches, and support staff must have understand of the integrity of sport through anti-doping education.

Professor Jigoro Kano, who developed judo from jujutsu in 1882, founded the Kodokan Institute for the instruction of judo. $\mathrm{He}$ expressed a similar opinion that emphasized the importance of education through judo. The principles and aims of judo can be characterized by one of its main aspects, "Jundo Seisho", or "victory by following the true path" [5]. Thus, there are obvious similarities between the fight against doping in sport and principles and aims of judo.

Various people in different fields support an athlete in competing. Coaches are important for athletes to establish themselves, and athletes are strongly influenced by their coaches in competing in their sport [6]. Therefore, coaches must also understand anti-doping programs and seek to preserve what is intrinsically valuable about sport. There are many anti-doping surveys designed for school students and athletes [7-10] however, research and comparisons that consider international comparisons of anti-doping in coaches is limited.

Therefore, in this study we conducted a survey on the anti-doping views of coaches located in different countries, coaching the same sport, as well on their understanding of how anti-doping is intrinsically valuable to sport. 
Citation: $\quad$ Yoko Tanabe, Colin Mclver, Joyce Heron, Satomi Suzuki, Takao Akama (2017) Anti-doping Awareness among British and Japanese Judo Coaches. J Sports Med Doping Stud 7: 191. doi:10.4172/2161-0673.1000191

Page 2 of 9

\section{Methods}

The protocol was revised and approved by the Ethics Committee on Human Research of Waseda University 2013-048. English questionnaires are approved at Loughborough University, Ethics Approvals (Human Participants) Sub-Committee October 2012.

This study focuses on several aspects in coaches instructing in judo clubs. A total of 74 coaches in the United Kingdom (UK) and 66 coaches in Japan (JPN) were investigated. This survey was conducted for coaches that are active coaching in UK and JPN judo clubs. The UK covered 74 judo coaches qualified as coaches certified by British Judo Association. Japan covered 66 judo coaches qualified as coaches certified by the All Japan Judo federation. UK coaches completed the questionnaire survey (in English) in November 2012, and JPN coaches completed the questionnaire survey (in Japanese) in May 2014. The questionnaire survey was prepared in English and in Japanese and the validity of the translation was checked by a specialist. In the UK, the British judo Association conducted e-mail and coach seminar, and collected them during e-mails and seminar. In Japan, it was held at a coach seminar, taking a form to collect on the spot. The questionnaire content was done in a form using choices by anonymous.

The questionnaire comprised several anti-doping items, consisting of social aspects, educational aspects, ethical aspects, and medical aspects (Tables 1-5). Questionnaire surveys were analyzed, and comparisons were made between all UK coaches (UK_ALL) and all JPN coaches (JPN_ALL), as well as between subgroups of UK coaches that had reviewed at least one anti-doping education workshop (UK_Y group) and had never attended such a workshop (UK_N group). Because only 3 Japanese coaches had never attended an anti-doping education workshops, only the group that had attended a workshop (JPN_Y group) underwent targeted analysis.

UK and JPN coaches' responses from Questions 4-7 were compared using the chi-square test (Question 4-6) and the Mann-Whitney U test (Question 7) in IBM SPSS Statistics version 21 for Windows. Statistical significance was set at $\mathrm{p}<0.05$. UK and JPN coaches' age responses were compared using independent $\mathrm{t}$-test calculated using IBM SPSS Statistics version 21 for Windows. Statistical significance was set at $\mathrm{p}<0.05$.

\section{Result}

Questions 1 "coaches' age". There was a total of 74 UK coaches (age $47.0 \pm 10.2$ years) and $66 \mathrm{JPN}$ coaches (age $50.3 \pm 8.4$ years), with JPN coaches significantly older.
Question 2 "gender". The gender ratio for UK coaches was 62 males and 12 females, and that for JPN coaches was 64 males and 2 females.

Question 3 "years of judo experience respectively". JPN coaches $(39.0 \pm 8.3$ years) had significantly more years of judo experience than UK coaches (31.1 \pm 11.7 years).

Question 4 was about knowledge of the National Anti-Doping Organization (NADO). 69 of the 74 UK coaches (93.2\%) responded that they knew of NADO and 5 responded (6.8\%) that they did not, whereas 58 of the 66 JPN coaches (87.9\%) responded that they knew of NADO and 8 responded (12.1\%) that they did not (Table 1 ).

Question 5 was about knowledge of the World Anti-Doping Agency (WADA). 56 UK coaches (75.7\%) responded that they knew of WADA and 18 responded $(24.3 \%)$ that they did not, and 50 JPN coaches $(75.7 \%)$ responded that they knew of WADA and 16 responded (24.2\%) that they did not (Table 1).

\begin{tabular}{|c|c|c|c|c|}
\hline & & Yes & No & $\mathbf{P}$ \\
\hline \multirow{2}{*}{$\begin{array}{l}\text { Q4. Do you know the } \\
\text { National Anti-Doping } \\
\text { Organization (NADO)? }\end{array}$} & UK_ALL & $69(93.2 \%)$ & $5(6.8 \%)$ & \multirow{2}{*}{0.275} \\
\hline & JPN_ALL & $58(87.9 \%)$ & $8(12.1 \%)$ & \\
\hline \multirow{2}{*}{$\begin{array}{l}\text { Q5. Do you know the } \\
\text { World Anti-Doping } \\
\text { Agency (WADA)? }\end{array}$} & UK_ALL & $56(75.7 \%)$ & $18(24.3 \%)$ & \multirow{2}{*}{0.991} \\
\hline & JPN_ALL & $50(75.8 \%)$ & $16(24.2 \%)$ & \\
\hline $\begin{array}{c}n=74(\text { (UK_ALL) } n=66 \\
\text { (JPN_ALL) }\end{array}$ & & & & \\
\hline
\end{tabular}

Table 1: Knowledge of the National Anti-Doping Organization (NADO) and the World Anti-Doping Agency(WADA).

Question 6 regarded coaches' opportunity to attend anti-doping. 46 of the 74 UK coaches (62.2\%) responded that they had never attended a workshop, and 20 responded $(27.0 \%)$ that they had attended at least once, whereas 3 of the 66 JPN coaches (4.6\%) who responded that they have never attended the workshops, and 14 responded $(21.2 \%)$ that they have attended once (Table 2).

\begin{tabular}{|c|c|c|c|c|c|c|c|}
\hline Q6. How often have you attended anti-doping workshops? \\
\hline \multirow{2}{*}{} & Never Attended & Attended Once & $\begin{array}{c}\text { Attended Once a } \\
\text { Month }\end{array}$ & $\begin{array}{c}\text { Attended Twice } \\
\text { a Year }\end{array}$ & $\begin{array}{c}\text { Attended Once a } \\
\text { Year }\end{array}$ & $\begin{array}{c}\text { Attended Once } \\
\mathbf{2 - 3} \text { Years }\end{array}$ & $\begin{array}{c}\text { P } \\
\text { UK_ALL }\end{array}$ \\
\cline { 2 - 7 } & 46 & 20 & 0 & 1 & 4 & $4.10 \%$ \\
\hline \multirow{2}{*}{ JPN_ALL } & $62.20 \%$ & $27.00 \%$ & $0.00 \%$ & $1.40 \%$ & $5.40 \%$ & 22 \\
\cline { 2 - 7 } & 4 & 14 & 0 & 1 & 26 & $3.000^{*}$ \\
\hline
\end{tabular}


Citation: $\quad$ Yoko Tanabe, Colin Mclver, Joyce Heron, Satomi Suzuki, Takao Akama (2017) Anti-doping Awareness among British and Japanese Judo Coaches. J Sports Med Doping Stud 7: 191. doi:10.4172/2161-0673.1000191

Page 3 of 9

$\mathrm{n}=74(\mathrm{UK}$ ALL)

$\mathrm{n}=66$ (JPN_ALL)

Table 2: Coaches' opportunity to attend anti-doping.

Question 7 was divided into 10 sub-questions that aimed to compare the two countries' views of doping in terms of social, educational, ethical, and health-related aspects. The first set of comparisons was between the UK_ALL $(\mathrm{n}=74)$ and JPN_ALL groups $(\mathrm{n}=66)$ (Table 3).

Responses to Question 7.1, "I agree with the act of doping", indicated that 41 coaches in UK_ALL (55.4\%) responded that they "Strongly disagree" and $31(41.9 \%)$ responded that they "Strongly agree", whereas in JPN_ALL, 49 coaches (74.2\%) responded that they "Strongly disagree", and 9 (13.6\%) responded that they "Strongly agree", representing a significant difference between groups.

In Question 7.2, "Doping is anti-fair play", Question 7.3 "Doping is an anti-social activity or behavior", Question 7.4 "Doping threatens athletes' health", and Question 7.5 "Doping depreciates the value of judo", "Strongly agree" was the most common response, and there were no significant differences between the UK_ALL group and JPN_ALL group.

In Question 7.6 "Doping enables judoka to improve their performance", 21 coaches in UK_ALL (28.4\%) responded that they "Agree" and 21 coaches (28.4\%) responded that they "Strongly agree"; whereas 39 coaches in JPN_ALL (59.1\%) responded that they "Strongly disagree", indicating a significant difference between groups.
In Question 7.7, "The meaning of sports is to do anything to win", 34 coaches in the UK_ALL group (45.9\%) and 34 in the JPN_ALL group (51.5\%) responded "Disagree". There was no significant difference in responses between groups.

In Question 7.8, "It would not be a problem to dope in order to win a competition", 58 coaches in the UK_ALL group (78.4\%) and 58 in the JPN_ALL group (87.9\%) responded "Strongly disagree", with no significant differences in responses between groups.

In Question 7.9, "Prohibited substances are possibly included in certain legal medicines and food supplements" showed that 30 coaches in the UK_ALL group (40.5\%) responded that they "Don't know", 32 in the JPN_ALL group (48.5\%) responded that they "Agree", and 21 in the JPN_ALL group (31.8\%) responded that they "Strongly agree". The difference in responses between the groups was statistically significant.

In Question 7.10, "I believe that anti-doping and the intrinsic value of sports are the same", 15 coaches in the UK_ALL group (20.3\%) and 33 in the JPN_ALL group (50.0\%) responded that they "Strongly agree". There was no significant difference between two groups.

\begin{tabular}{|c|c|c|c|c|c|c|c|c|}
\hline \multirow[t]{2}{*}{ Q7. UK_ALL and JPN_ALL } & \multicolumn{6}{|c|}{ (n) } & \multirow[t]{2}{*}{ M: Median } & \multirow[t]{2}{*}{$\mathbf{P}$} \\
\hline & & $\begin{array}{l}\text { 1. Strongly } \\
\text { Disagree }\end{array}$ & 2. Disagree & 3. Don't know & 4. Agree & $\begin{array}{l}\text { 5. Strongly } \\
\text { Agree }\end{array}$ & & \\
\hline \multirow{4}{*}{$\begin{array}{l}\text { Q7.1 I agree with the } \\
\text { action of doping. }\end{array}$} & \multirow{2}{*}{ UK_ALL } & 41 & 0 & 0 & 2 & 31 & \multirow{2}{*}{1} & \multirow{4}{*}{0.004 * } \\
\hline & & $55.40 \%$ & $0.00 \%$ & $0.00 \%$ & $2.70 \%$ & $42.90 \%$ & & \\
\hline & \multirow{2}{*}{ JPN_ALL } & 49 & 3 & 2 & 3 & 9 & \multirow{2}{*}{1} & \\
\hline & & $74.20 \%$ & $4.50 \%$ & $3.00 \%$ & $4.50 \%$ & $13.60 \%$ & & \\
\hline \multirow{4}{*}{$\begin{array}{l}\text { Q7.2 Doping is anti-fair } \\
\text { play. }\end{array}$} & \multirow{2}{*}{ UK_ALL } & 9 & 2 & 1 & 5 & 57 & \multirow{2}{*}{5} & \multirow{4}{*}{0.568} \\
\hline & & $12.20 \%$ & $2.70 \%$ & $1.40 \%$ & $6.80 \%$ & $77.00 \%$ & & \\
\hline & \multirow{2}{*}{ JPN_ALL } & 6 & 0 & 0 & 7 & 53 & \multirow{2}{*}{5} & \\
\hline & & $9.10 \%$ & $0.00 \%$ & $0.00 \%$ & $10.60 \%$ & $80.30 \%$ & & \\
\hline \multirow{4}{*}{$\begin{array}{l}\text { Q7.3 Doping is an anti- } \\
\text { social activity or behavior. }\end{array}$} & \multirow{2}{*}{ UK_ALL } & 8 & 5 & 7 & 7 & 47 & \multirow{2}{*}{5} & \multirow{4}{*}{0.215} \\
\hline & & $10.80 \%$ & $6.80 \%$ & $9.50 \%$ & $9.50 \%$ & $63.50 \%$ & & \\
\hline & \multirow{2}{*}{ JPN_ALL } & 5 & 2 & 1 & 11 & 47 & \multirow{2}{*}{5} & \\
\hline & & $7.60 \%$ & $3.00 \%$ & $1.50 \%$ & $16.70 \%$ & $71.20 \%$ & & \\
\hline \multirow{3}{*}{$\begin{array}{l}\text { Q7.4 Doping threatens } \\
\text { athlete's health }\end{array}$} & \multirow{2}{*}{ UK_ALL } & 6 & 0 & 6 & 14 & 48 & \multirow{2}{*}{5} & \multirow{3}{*}{0.248} \\
\hline & & $8.10 \%$ & $0.00 \%$ & $8 \%$ & $18.90 \%$ & $64.90 \%$ & & \\
\hline & JPN_ALL & 6 & 0 & 1 & 10 & 49 & 5 & \\
\hline
\end{tabular}


Citation: $\quad$ Yoko Tanabe, Colin Mclver, Joyce Heron, Satomi Suzuki, Takao Akama (2017) Anti-doping Awareness among British and Japanese Judo Coaches. J Sports Med Doping Stud 7: 191. doi:10.4172/2161-0673.1000191

Page 4 of 9

\begin{tabular}{|c|c|c|c|c|c|c|c|c|}
\hline & & $9.00 \%$ & $0.00 \%$ & $1.50 \%$ & $15.10 \%$ & $74.20 \%$ & & \\
\hline \multirow{4}{*}{$\begin{array}{l}\text { Q7.5 Doping depreciates } \\
\text { the value of Judo }\end{array}$} & \multirow{2}{*}{ UK_ALL } & 6 & 1 & 2 & 6 & 59 & \multirow{2}{*}{5} & \multirow{4}{*}{0.627} \\
\hline & & $8.10 \%$ & $1.40 \%$ & $2.70 \%$ & $8.10 \%$ & $79.70 \%$ & & \\
\hline & \multirow{2}{*}{ JPN_ALL } & 6 & 1 & 0 & 9 & 50 & \multirow{2}{*}{5} & \\
\hline & & $9.00 \%$ & $1.50 \%$ & $0.00 \%$ & $13.60 \%$ & $75.80 \%$ & & \\
\hline \multirow{4}{*}{$\begin{array}{l}\text { Q7.6 Doping enables } \\
\text { Judoka to improve their } \\
\text { performance. }\end{array}$} & \multirow{2}{*}{ UK_ALL } & 13 & 5 & 14 & 21 & 21 & \multirow{2}{*}{4} & \multirow{4}{*}{0.000 * } \\
\hline & & $17.60 \%$ & $6.80 \%$ & $18.90 \%$ & $28.40 \%$ & $28.40 \%$ & & \\
\hline & \multirow{2}{*}{ JPN_ALL } & 39 & 11 & 9 & 2 & 5 & \multirow{2}{*}{1} & \\
\hline & & $59.10 \%$ & $16.70 \%$ & $13.60 \%$ & $3.00 \%$ & $7.60 \%$ & & \\
\hline \multirow{4}{*}{$\begin{array}{l}\text { Q7.7 The meaning } \\
\text { (purpose) of sports is all for } \\
\text { the victory. }\end{array}$} & \multirow{2}{*}{ UK_ALL } & 29 & 34 & 6 & 2 & 3 & \multirow{2}{*}{2} & \multirow{4}{*}{0.561} \\
\hline & & $39.20 \%$ & $45.90 \%$ & $8.10 \%$ & $2.70 \%$ & $4.10 \%$ & & \\
\hline & \multirow{2}{*}{ JPN_ALL } & 22 & 34 & 4 & 5 & 1 & \multirow{2}{*}{2} & \\
\hline & & $33.30 \%$ & $51.50 \%$ & $6.00 \%$ & $7.60 \%$ & $1.50 \%$ & & \\
\hline \multirow{4}{*}{$\begin{array}{l}\text { Q7.8 It would not be a } \\
\text { problem to dope in order to } \\
\text { win a competition. }\end{array}$} & \multirow{2}{*}{ UK_ALL } & 58 & 6 & 1 & 1 & 8 & \multirow{2}{*}{1} & \multirow{4}{*}{0.094} \\
\hline & & $78.40 \%$ & $8.10 \%$ & $1.40 \%$ & $1.40 \%$ & $10.80 \%$ & & \\
\hline & \multirow{2}{*}{ JPN_ALL } & 58 & 7 & 0 & 0 & 1 & 1 & \\
\hline & & $87.90 \%$ & $10.60 \%$ & $0.00 \%$ & $0.00 \%$ & $1.50 \%$ & & \\
\hline \multirow{4}{*}{$\begin{array}{l}\text { Q7.9 Prohibited } \\
\text { substances are possibly } \\
\text { involved in a kind of food } \\
\text { supplements and } \\
\text { medicine. }\end{array}$} & \multirow{2}{*}{ UK_ALL } & 5 & 2 & 30 & 22 & 15 & \multirow{2}{*}{3.5} & \multirow{4}{*}{0.001 * } \\
\hline & & $6.80 \%$ & $3 \%$ & $40.50 \%$ & $29.70 \%$ & $20.30 \%$ & & \\
\hline & \multirow{2}{*}{ JPN_ALL } & 1 & 1 & 11 & 32 & 21 & \multirow{2}{*}{4} & \\
\hline & & $1.50 \%$ & $1.50 \%$ & $16.70 \%$ & $48.50 \%$ & $31.80 \%$ & & \\
\hline \multirow{4}{*}{$\begin{array}{l}\text { Q7.10 I believe that anti- } \\
\text { doping and sports intrinsic } \\
\text { values are the same. }\end{array}$} & \multirow{2}{*}{ UK_ALL } & 3 & 7 & 16 & 12 & 36 & \multirow{2}{*}{4} & \\
\hline & & $4.00 \%$ & $10 \%$ & $22 \%$ & $16.20 \%$ & $48.60 \%$ & & \\
\hline & & 1 & 0 & 8 & 24 & 33 & & \\
\hline & - & $1.50 \%$ & $0.00 \%$ & $12.10 \%$ & $36.40 \%$ & $50.00 \%$ & 4.0 & \\
\hline $\begin{array}{c}\mathrm{n}=74(\text { UK_ALL) } \mathrm{n}=66 \\
\text { (JPN_ALL) }\end{array}$ & & & & & & & & \\
\hline
\end{tabular}

Table 3: Comparison of UK_ALL and JPN_ALL countries' views of doping.

The second set of comparisons was between the UK_Y group $(\mathrm{n}=28)$ and the JPN_Y group $(\mathrm{n}=63)$ (Table 4$)$.

In Question 7.1, "I agree with the act of doping", indicated that 14 coaches in the UK_Y group (50\%) responded "Strongly disagree" and $14(50.0 \%)$ responded "Strongly agree", whereas 48 coaches in JPN_Y $(76.2 \%)$ responded "Strongly disagree", representing a statistically significant difference between groups.

In Question 7.2, "Doping is anti-fair play", Question 7.3 "Doping is an anti-social activity or behavior", Question 7.4 "Doping threatens athletes' health", and Question 7.5 "Doping depreciates the value of judo", indicated that "Strongly agree" was the most common responses, and there were no significant differences between groups.
In Question 7.6 "Doping enables judoka to improve their performance", indicated that 8 coaches in the UK_Y group (28.6\%) responded "Agree" and 8 (28.6\%) responded "Strongly agree". However, 37 coaches in the JPN_Y group (58.7\%) responded "Strongly disagree". There was significant difference between the UK_Y group and JPN_Y group.

In Question 7.7, “The meaning of sports is to do anything to win", 13 coaches in the UK_Y group (46.4\%) and 34 in the JPN_Y group $(54.0 \%)$ responded "Disagree". The mean difference in response between the groups was not significant.

In Question 7.8, "It would not be a problem to dope in order to win a competition", 22 coaches in the UK_Y group (78.6\%) and 55 in JPN_Y group (87.3\%) responded. 
Citation: $\quad$ Yoko Tanabe, Colin Mclver, Joyce Heron, Satomi Suzuki, Takao Akama (2017) Anti-doping Awareness among British and Japanese Judo Coaches. J Sports Med Doping Stud 7: 191. doi:10.4172/2161-0673.1000191

Page 5 of 9

"Strongly disagree". There was no significant difference between the UK_Y group and JPN_Y group.

In Question 7.9, "Prohibited substances are possibly included in certain legal medicines and food supplements" showed that 7 coaches in the UK_Y group (25.9\%) responded "Don't know" and 13 (46.4\%) responded "Agree", whereas 31 in the JPN_Y group (49.2\%) responded that "Agree" and 21 (33.3\%) responded "Strongly agree". The mean difference between the UK_Y group and JPN_Y group was statistically significant.

In Question 7.10, "I believe that anti-doping and the intrinsic value of sports are the same", 15 coaches in the UK_Y group (53.6\%) and 32 in the JPN_Y group (50.8\%) responded that "Strongly agree". The mean difference between the UK_Y group and JPN_Y group was not significant.
Finally, comparisons were made between the UK_Y group $(n=28)$ and UK_N group $(\mathrm{n}=46)$ (Table 5).

In Question 7.1, "I agree with the act of doping", indicated that 27 coaches in UK_N (58.7\%) responded "Strongly disagree", and 17 $(37.0 \%)$ responded "Strongly agree".

There was no significant difference between the UK_Y group and UK_N group.

In Question 7.2, "Doping is anti-fair play", Question 7.3 "Doping is an anti-social activity or behavior", Question 7.4 "Doping threatens athletes' health", and Question 7.5 "Doping depreciates the value of judo", indicated that, "Strongly agree" was the most common response, and there was no significant difference between groups.

\begin{tabular}{|c|c|c|c|c|c|c|c|c|}
\hline \multirow{2}{*}{ Q7. UK_Y and JPN_Y } & \multicolumn{6}{|c|}{ (n) } & \multirow[t]{2}{*}{ M: Median } & \multirow[t]{2}{*}{$\mathbf{P}$} \\
\hline & & $\begin{array}{l}\text { 1. Strongly } \\
\text { Disagree }\end{array}$ & 2. Disagree & $\begin{array}{l}\text { 3. Don't } \\
\text { know }\end{array}$ & 4. Agree & $\begin{array}{l}\text { 5. Strongly } \\
\text { Agree }\end{array}$ & & \\
\hline \multirow{4}{*}{$\begin{array}{l}\text { Q7.1 I agree with the action } \\
\text { of doping. }\end{array}$} & \multirow{2}{*}{ UK_Y } & 14 & 0 & 0 & 0 & 14 & \multirow{2}{*}{3} & \multirow{4}{*}{0.003 * } \\
\hline & & $50.00 \%$ & $0.00 \%$ & $0.00 \%$ & $0.00 \%$ & $50.00 \%$ & & \\
\hline & \multirow{2}{*}{ JPN_Y } & 48 & 3 & 1 & 3 & 8 & \multirow{2}{*}{1} & \\
\hline & & $76.20 \%$ & $4.80 \%$ & $1.60 \%$ & $4.80 \%$ & $12.70 \%$ & & \\
\hline \multirow{4}{*}{ Q7.2 Doping is anti-fair play. } & \multirow{2}{*}{ UK_Y } & 4 & 1 & 1 & 2 & 20 & \multirow{2}{*}{5} & \multirow{4}{*}{0.356} \\
\hline & & $14.30 \%$ & $3.60 \%$ & $3.60 \%$ & $7.10 \%$ & $71.40 \%$ & & \\
\hline & \multirow{2}{*}{ JPN_Y } & 6 & 0 & 0 & 7 & 50 & \multirow{2}{*}{5} & \\
\hline & & $9.50 \%$ & $0.00 \%$ & $0.00 \%$ & $11.10 \%$ & $79.40 \%$ & & \\
\hline \multirow{4}{*}{$\begin{array}{l}\text { Q7.3 Doping is an anti- } \\
\text { social activity or behavior. }\end{array}$} & \multirow{2}{*}{ UK_Y } & 3 & 2 & 2 & 1 & 20 & \multirow{2}{*}{5} & \multirow{4}{*}{0.881} \\
\hline & & $10.70 \%$ & $10.70 \%$ & $10.70 \%$ & $3.60 \%$ & $71.40 \%$ & & \\
\hline & \multirow{2}{*}{ JPN_Y } & 5 & 2 & 1 & 11 & 44 & \multirow{2}{*}{5} & \\
\hline & & $7.90 \%$ & $3.20 \%$ & $1.60 \%$ & $17.50 \%$ & $69.80 \%$ & & \\
\hline \multirow{4}{*}{$\begin{array}{l}\text { Q7.4 Doping threatens } \\
\text { athlete's health }\end{array}$} & \multirow{2}{*}{ UK_Y } & 2 & 0 & 1 & 5 & 20 & \multirow{2}{*}{5} & \multirow{4}{*}{0.917} \\
\hline & & $10.70 \%$ & $0.00 \%$ & $4 \%$ & $17.90 \%$ & $71.40 \%$ & & \\
\hline & \multirow{2}{*}{ JPN_Y } & 6 & 0 & 1 & 10 & 46 & \multirow{2}{*}{5} & \\
\hline & & $9.50 \%$ & $0.00 \%$ & $1.60 \%$ & $15.90 \%$ & $73.00 \%$ & & \\
\hline \multirow{4}{*}{$\begin{array}{l}\text { Q7.5 Doping depreciates } \\
\text { the value of Judo }\end{array}$} & UK_Y & 1 & 0 & 2 & 0 & 25 & \multirow{2}{*}{5} & \multirow{4}{*}{0.138} \\
\hline & & $3.60 \%$ & $0.00 \%$ & $10.70 \%$ & $0.00 \%$ & $89.30 \%$ & & \\
\hline & \multirow{2}{*}{ JPN_Y } & 6 & 1 & 0 & 9 & 47 & & \\
\hline & & $9.50 \%$ & $1.60 \%$ & $0.00 \%$ & $9.50 \%$ & $74.60 \%$ & & \\
\hline & IN & 6 & 1 & 5 & 8 & 8 & 1 & \\
\hline $\begin{array}{l}\text { Q7.6 Doping enables } \\
\text { Judoka to improve their }\end{array}$ & & $21.40 \%$ & $3.60 \%$ & $17.90 \%$ & $28.60 \%$ & $28.60 \%$ & & 0000 * \\
\hline performance. & IPN Y & 37 & 10 & 9 & 2 & 5 & 1 & \\
\hline & & $58.70 \%$ & $15.90 \%$ & $14.30 \%$ & $3.20 \%$ & $7.90 \%$ & & \\
\hline
\end{tabular}


Citation: $\quad$ Yoko Tanabe, Colin Mclver, Joyce Heron, Satomi Suzuki, Takao Akama (2017) Anti-doping Awareness among British and Japanese Judo Coaches. J Sports Med Doping Stud 7: 191. doi:10.4172/2161-0673.1000191

Page 6 of 9

\begin{tabular}{|c|c|c|c|c|c|c|c|c|}
\hline \multirow{4}{*}{$\begin{array}{l}\text { Q7.7 The meaning } \\
\text { (purpose) of sports is all for } \\
\text { the victory. }\end{array}$} & \multirow{2}{*}{ UK_Y } & 11 & 13 & 3 & 1 & 0 & \multirow{2}{*}{2} & \multirow{4}{*}{0.538} \\
\hline & & $39.30 \%$ & $46 \%$ & $10.70 \%$ & $3.60 \%$ & $0.00 \%$ & & \\
\hline & \multirow{2}{*}{ JPN_Y } & 20 & 34 & 3 & 5 & 1 & \multirow{2}{*}{2} & \\
\hline & & $31.70 \%$ & $54.00 \%$ & $4.80 \%$ & $7.90 \%$ & $1.60 \%$ & & \\
\hline \multirow{4}{*}{$\begin{array}{l}\text { Q7.8 It would not be a } \\
\text { problem to dope in order to } \\
\text { win a competition. }\end{array}$} & \multirow{2}{*}{ UK_Y } & 22 & 2 & 0 & 1 & 3 & \multirow{2}{*}{1} & \multirow{4}{*}{0.22} \\
\hline & & $78.60 \%$ & $10.70 \%$ & $0.00 \%$ & $3.60 \%$ & $10.70 \%$ & & \\
\hline & \multirow{2}{*}{$J P N \_Y$} & 55 & 7 & 0 & 0 & 1 & \multirow{2}{*}{1} & \\
\hline & & $87.30 \%$ & $11.10 \%$ & $0.00 \%$ & $0.00 \%$ & $1.60 \%$ & & \\
\hline \multirow{4}{*}{$\begin{array}{l}\text { Q7.9 Prohibited substances } \\
\text { are possibly involved in a } \\
\text { kind of food supplements } \\
\text { and medicine. }\end{array}$} & \multirow{2}{*}{ UK_Y } & 3 & 1 & 7 & 13 & 4 & \multirow{2}{*}{4} & \multirow{4}{*}{0.010 * } \\
\hline & & $10.70 \%$ & $3.60 \%$ & $25.00 \%$ & $46.40 \%$ & $14.30 \%$ & & \\
\hline & \multirow{2}{*}{ JPN_Y } & 1 & 1 & 9 & 31 & 21 & \multirow{2}{*}{4} & \\
\hline & & $1.60 \%$ & $1.60 \%$ & $14.30 \%$ & $49.20 \%$ & $33.30 \%$ & & \\
\hline \multirow{4}{*}{$\begin{array}{l}\text { Q7.10 I believe that anti- } \\
\text { doping and sports intrinsic } \\
\text { values are the same. }\end{array}$} & \multirow{2}{*}{ UK_Y } & 1 & 5 & 4 & 3 & 15 & \multirow{2}{*}{5} & \multirow{4}{*}{0.372} \\
\hline & & $3.60 \%$ & $17.90 \%$ & $14.30 \%$ & $10.70 \%$ & $53.60 \%$ & & \\
\hline & \multirow{2}{*}{ JPN_Y } & 1 & 0 & 7 & 23 & 32 & \multirow{2}{*}{5} & \\
\hline & & $1.60 \%$ & $0.00 \%$ & $11.10 \%$ & $36.50 \%$ & $50.80 \%$ & & \\
\hline$n=28($ UK_Y $) n=63\left(J P N \_Y\right)$ & & & & & & & & \\
\hline
\end{tabular}

Table 4: Comparison of UK_Y and JPN_Y countries' views of doping.

In Question 7.6 "Doping enables judoka to improve their performance", indicated that 13 coaches in the UK_N group (28.3\%) responded "Agree" and 8 in the UK_N group (28.3\%) responded "Strongly agree". There was no significant difference between the groups.
In Question 7.7, “The meaning of sports is to do anything to win”, 18 coaches in the UK_N group (39.1\%) responded "Strongly disagree" and 21 in the UK_N group (45.7\%) responded "Disagree".

\begin{tabular}{|c|c|c|c|c|c|c|c|c|}
\hline \multirow[b]{2}{*}{ Q7. UK_Y and UK_N } & & \multicolumn{5}{|c|}{ (n) } & \multirow[t]{2}{*}{ M: Median } & \multirow[t]{2}{*}{$\mathbf{P}$} \\
\hline & & $\begin{array}{l}\text { 1. Strongly } \\
\text { Disagree }\end{array}$ & 2. Disagree & 3. Don't know & 4. Agree & $\begin{array}{l}\text { 5. Strongly } \\
\text { Agree }\end{array}$ & & \\
\hline \multirow{4}{*}{$\begin{array}{c}\text { Q7.1 I agree with the action } \\
\text { of doping }\end{array}$} & \multirow{2}{*}{ UK_Y } & 14 & 0 & 0 & 0 & 14 & \multirow{2}{*}{3} & \multirow{4}{*}{0.37} \\
\hline & & $50.00 \%$ & $0.00 \%$ & $0.00 \%$ & $0.00 \%$ & $50.00 \%$ & & \\
\hline & \multirow{2}{*}{ UK_N } & 27 & 0 & 0 & 2 & 17 & \multirow{2}{*}{1} & \\
\hline & & $58.70 \%$ & $0.00 \%$ & $0.00 \%$ & $4.30 \%$ & $37.00 \%$ & & \\
\hline \multirow{4}{*}{ Q7.2 Doping is anti-fair play } & \multirow{2}{*}{ UK_Y } & 4 & 1 & 1 & 2 & 20 & \multirow{2}{*}{5} & \multirow{4}{*}{0.384} \\
\hline & & $14.30 \%$ & $3.80 \%$ & $3.80 \%$ & $7.10 \%$ & $71.40 \%$ & & \\
\hline & \multirow{2}{*}{ UK_N } & 5 & 1 & 0 & 3 & 37 & \multirow{2}{*}{5} & \\
\hline & & $10.90 \%$ & $2.20 \%$ & $0.00 \%$ & $6.50 \%$ & $80.40 \%$ & & \\
\hline \multirow{3}{*}{$\begin{array}{l}\text { Q7.3 Doping is an anti-social } \\
\text { activity or behavior }\end{array}$} & \multirow{2}{*}{ UK_Y } & 3 & 2 & 2 & 2 & 20 & \multirow{2}{*}{5} & \multirow{3}{*}{0.411} \\
\hline & & $10.70 \%$ & $7.10 \%$ & $7.10 \%$ & $7.10 \%$ & $71.40 \%$ & & \\
\hline & UK_N & 5 & 3 & 5 & 6 & 27 & 5 & \\
\hline
\end{tabular}


Citation: $\quad$ Yoko Tanabe, Colin Mclver, Joyce Heron, Satomi Suzuki, Takao Akama (2017) Anti-doping Awareness among British and Japanese Judo Coaches. J Sports Med Doping Stud 7: 191. doi:10.4172/2161-0673.1000191

Page 7 of 9

\begin{tabular}{|c|c|c|c|c|c|c|c|c|}
\hline & & $10.90 \%$ & $6.50 \%$ & $10.90 \%$ & $13.00 \%$ & $58.70 \%$ & & \\
\hline \multirow{4}{*}{$\begin{array}{l}\text { Q7.4 Doping threatens } \\
\text { athlete's health }\end{array}$} & \multirow{2}{*}{ UK_Y } & 2 & 0 & 1 & 5 & 20 & \multirow{2}{*}{5} & \multirow{4}{*}{0.331} \\
\hline & & $7.10 \%$ & $0.00 \%$ & $4 \%$ & $17.90 \%$ & $71.40 \%$ & & \\
\hline & \multirow{2}{*}{ UK_N } & 4 & 0 & 5 & 9 & 28 & \multirow{2}{*}{5} & \\
\hline & & $8.70 \%$ & $0.00 \%$ & $10.90 \%$ & $19.60 \%$ & $60.90 \%$ & & \\
\hline \multirow{4}{*}{$\begin{array}{l}\text { Q7.5 Doping depreciates the } \\
\text { value of Judo }\end{array}$} & \multirow{2}{*}{ UK_Y } & 1 & 0 & 2 & 0 & 25 & \multirow{2}{*}{5} & \multirow{4}{*}{0.129} \\
\hline & & $3.80 \%$ & $0.00 \%$ & $7.10 \%$ & $0.00 \%$ & $89.30 \%$ & & \\
\hline & \multirow{2}{*}{ UK_N } & 5 & 1 & 0 & 6 & 34 & \multirow{2}{*}{5} & \\
\hline & & $10.90 \%$ & $2.20 \%$ & $0.00 \%$ & $13.00 \%$ & $73.90 \%$ & & \\
\hline \multirow{4}{*}{$\begin{array}{l}\text { Q7.6 Doping enables Judoka } \\
\text { to improve their performance }\end{array}$} & \multirow{2}{*}{ UK_Y } & 6 & 1 & 5 & 8 & 8 & \multirow{2}{*}{4} & \multirow{4}{*}{0.922} \\
\hline & & $21.40 \%$ & $3.80 \%$ & $17.90 \%$ & $28.60 \%$ & $28.60 \%$ & & \\
\hline & \multirow{2}{*}{ UK_N } & 7 & 4 & 9 & 13 & 13 & \multirow{2}{*}{4} & \\
\hline & & $15.20 \%$ & $8.70 \%$ & $19.60 \%$ & $28.30 \%$ & $28.30 \%$ & & \\
\hline \multirow{4}{*}{$\begin{array}{l}\text { Q7.7 The meaning (purpose) } \\
\text { of sports is all for the victory }\end{array}$} & \multirow{2}{*}{ UK_Y } & 11 & 13 & 3 & 1 & 0 & \multirow{2}{*}{2} & \multirow{4}{*}{0.899} \\
\hline & & $39.30 \%$ & $46.40 \%$ & $10.70 \%$ & $3.80 \%$ & $0.00 \%$ & & \\
\hline & \multirow{2}{*}{ UK_N } & 18 & 21 & 3 & 1 & 3 & \multirow{2}{*}{2} & \\
\hline & & $39.10 \%$ & $45.70 \%$ & $6.50 \%$ & $2.20 \%$ & $6.50 \%$ & & \\
\hline \multirow{4}{*}{$\begin{array}{l}\text { Q7.8 It would not be a } \\
\text { problem to dope in order to } \\
\text { win a competition }\end{array}$} & \multirow{2}{*}{ UK_Y } & 22 & 2 & 0 & 1 & 3 & \multirow{2}{*}{1} & \multirow{4}{*}{0.994} \\
\hline & & $78.60 \%$ & $7.10 \%$ & $0.00 \%$ & $3.80 \%$ & $10.70 \%$ & & \\
\hline & \multirow{2}{*}{ UK_N } & 36 & 4 & 1 & 0 & 5 & \multirow{2}{*}{1} & \\
\hline & & $78.30 \%$ & $8.70 \%$ & $2.20 \%$ & $0.00 \%$ & $10.90 \%$ & & \\
\hline & & 3 & 1 & 7 & 13 & 4 & & \\
\hline $\begin{array}{l}\text { Q7.9 Prohibited substances } \\
\text { are possibly involved in a }\end{array}$ & - & $10.70 \%$ & $4 \%$ & $25 \%$ & $46.40 \%$ & $14.30 \%$ & & \\
\hline $\begin{array}{l}\text { Kind or ood suppiements } \\
\text { and medicine }\end{array}$ & & 2 & 1 & 23 & 9 & 11 & & \\
\hline & & $4.30 \%$ & $2.20 \%$ & $50.00 \%$ & $19.60 \%$ & $23.90 \%$ & & \\
\hline & & 1 & 5 & 4 & 3 & 15 & & \\
\hline Q7.10 I believe that anti- & & $3.80 \%$ & $18 \%$ & $14 \%$ & $10.70 \%$ & $53.60 \%$ & & 0943 \\
\hline values are the same & & 2 & 2 & 12 & 9 & 21 & 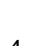 & \\
\hline & & $4.30 \%$ & $4.30 \%$ & $26.00 \%$ & $19.60 \%$ & $45.70 \%$ & & \\
\hline n=28 (UK_Y) n=46 (UK_N) & & & & & & & & \\
\hline
\end{tabular}

Table 5: Comparison UK_Y and UK_N countries' views of doping.

In Question 7.8, "It would not be a problem to dope in order to win a competition", 36 in the UK_N group (78.3\%) responded "Strongly disagree".

In Question 7.9, "Prohibited substances are possibly included in certain legal medicines and food supplements" showed that 23 coaches in the UK_N group (50.0\%) responded "Don’t know".

In Question 7.10, "I believe that anti-doping and the intrinsic value of sports are the same", 15 coaches in the UK_Y group (53.6\%) and 21 in the UK_N group (45.7\%) responded "Strongly agree". For each question, there was no significant difference between the UK_Y and UK_N group.

\section{Discussion}

The surveys focused on different aspects of the same sport, with coaches from different countries providing their views on anti-doping and their understanding of the intrinsic value of sport. A total of 74 
UK judo coaches and 66 JPN judo coaches certified by the British Judo Federation or the All Japan Judo Federation participated in the survey.

Questions 1-3 obtained basic participant data of age, gender, and years of judo experience. Results indicated that the age of UK and JPN coaches was significantly different. Both countries had more male than female coaches, but years of judo experience were significantly different between UK and JPN, however both countries coaches had over 30 years of judo experience. Coaches in both countries have sufficient years of judo experience and a deep understanding of judo; therefore, participants' age, gender, and years of judo experience are not expected to affect other obtained results.

Questions 4 and 5 regard knowledge of anti-doping institutions that establish rules and regulations. Both countries' coaches (UK_ALL group and JPN_ALL group) had a high awareness of the WADA and NADO institution.

Question 6 discusses coaches' opportunities to obtain anti-doping knowledge. Almost all (95.5\%) of the JPN_ALL group answered that they had attended anti-doping workshops; however, 46 coaches (62.2\%) from the UK_ALL group answered that they had never attended anti-doping workshops. This result shows that coaches have different opportunities for anti-doping education based on their country. Coaches in both countries are aware of the institutions that set anti-doping rules. JPN coaches might have learned about the WADA and NADO institutions from attending anti-doping workshops, but UK coaches may have learned about the institutions from a different source. For instance, UK coaches could have access to a brief overview of anti-doping through the WADA and United Kingdom Anti-Doping (UKAD) websites, and UK coaches are also encouraged to take the "Coaching Clean" UKAD online education module [11]. Similarly JPN coaches can take JADA anti-doping education online [12]. In this regard, online education provides coaches in both countries equal opportunities for anti-doping education. In addition, JPN coaches also have many opportunities to receive anti-doping training regionally. For example, JPN coaches have chances to attend anti-doping workshops before the annual National Sport Festival, which is not limited to only top-level coaches. For example, the 2014 National Sports Festival held in Wakayama Prefecture [13] launched the Sports Pharmacists system [14] for each sport and promoted the need for education on anti-doping for coaches. This indicates a difference in the way that JPN and UK consider the importance of anti-doping education, but whether they promote it through websites or workshops, both countries give coaches opportunities to learn anti-doping rules.

Question 7 aimed to compare the two countries' views of doping along the social, educational, ethical, and health-related aspects. The results from Question 7.1 (I agree with the act of doping), Question 7.6 (Doping enables judoka to improve their performance), and Question 7.9 (Prohibited substances are possibly included in certain legal medicines and food supplements) were significantly different between the UK and JPN groups.

The fundamental rationale for the code is protecting the intrinsic value of sport. This intrinsic value is often referred to as "the spirit of sport" and is reflected in the values found in the sport-related ethics of fair play, honesty of character, and the education around respect for rules and law [3]. Question 7.1 and Question 7.6 question whether there is a positive aspect to doping, and the results between UK and JPN were significantly different, despite expectations that they would be similar because the coaches, despite being in different countries, were coaching the same sport.

This study is limited to judo competition, but doping is fundamentally contrary to the spirit of all sports. Because coaches are a strong influence on athletes [15], and because athletes will come into contact with variety of coaches in the process of becoming competitive enough to compete in international tournaments, coaches at all levels should understand the fundamental rational for the World AntiDoping Code. Furthermore, for judo coaches specifically, it is necessary that to understand Kano's philosophy, which is similar that of "the spirit of sport".

Question 7.9 regards coaches' knowledge of supplements. At present, there can be no guarantee of the purity of any commercial supplement. Supplements use among athletes is widespread $[7,16]$, with by $62.7 \%$ of the Japanese national YOG team reporting that they used supplements for health and well-being [17]. It is necessary for coaches to raise athletes' awareness of the possibility that supplements may include substances prohibited under anti-doping regulations.

\section{Conclusion}

The anti-doping survey revealed that it is now known that coaches in both countries are aware of the institutions that establish antidoping rules and regulation, but that nevertheless, the views regarding the understanding of doping differ between the UK and Japan. Furthermore, there are similarities between the anti-doping fundamental rational of intrinsic value in sport, as defined by the "Play True" philosophy, and Kano's ethos in judo of jundo seisho. Therefore, judo coaches around the world should be educated on anti-doping regimes.

\section{References}

1. International Olympic Committee (2012) IOC Code of Ethics.

2. Singapore 2010 YOG.

3. World Anti-Doping Agency (2015) World Anti-Doping Code.

4. Japan Anti-Doping Agency (2014) For the future of our sports integrity.

5. Kawamura T, Daigo T (2000) Kodokan new Japanese-English dictionary of judo.

6. Japan Anti-Doping Agency (2010) Research paper of anti-doping education [Japanese].

7. Bloodworth A, McNamee M (2010) Clean Olympians? Doping and antidoping: The views of talented young British athletes. Int J Drug Policy 21: 276-282.

8. Watanabe SEK, Tsuyuki K, Ohe Y, Ohzeki Y, Anai Y (2010) Survey concerning "Anti-Doping" for junior-high-school Judo-players. Jap J Clin Sports Med 18: 20-26.

9. Kondo Y, Hasegawa E (2006) Report on the actual circumstances of students' anti-doping views in Undergraduate School of Health and Physical Education, University of Tsukuba. Bull Inst Health \& Sport Sci 30: 179-184.

10. Kondo Y, Hasegawa E (2008) Report on the present state of student's antidoping views in Undergraduate School of Health and Physical Education, University of Tsukuba. Bull Inst Health \& Sport Sci 32: 201-207.

11. http://ukad.org.uk/resources/document/uk-anti-doping-rules

12. http://www.playtruejapan.org/code/school/

13. http://www.pref.wakayama.lg.jp/chiji/press/260701/260701_1.pdf

14. Sports Pharmacist Share Goal (2015) Shared Mission. 
Citation: Yoko Tanabe, Colin Mclver, Joyce Heron, Satomi Suzuki, Takao Akama (2017) Anti-doping Awareness among British and Japanese Judo Coaches. J Sports Med Doping Stud 7: 191. doi:10.4172/2161-0673.1000191

Page 9 of 9

15. Tanabe Y, Asakawa S, Arakida Y, Kono I, Akama T (2015) Characteristics of the Japanese National Team of the First Youth Olympic Games. J Sports Med Doping Stud 5: 3-8.

16. Kim J, Lee N, Kim EJ, Ki SK, Yoon J, et al. (2011) Anti-doping education and dietary supplementation practice in Korean elite university athletes. Nutr Res Pract 5: 349-356.
17. Sato A, Kamei A, Kamihigashi E, Dohi M, Komatsu Y, et al. (2012) Use of supplements by young elite Japanese athletes participating in the 2010 youth Olympic games in Singapore. Clin J Sport Med 22: 418-423. 